Instructions for authors, subscriptions and further details:

http://brac.hipatiapress.com

\title{
Anell de Pedra. La Comella, 1976-2001. Rufino Mesa
}

Rufino Mesa ${ }^{1}$

1) Artista y Doctor en Bellas Artes

Date of publication: February $3^{\text {rd }}, 2015$

Edition period: February 2015 - June 2015

To cite this article: Mesa, R. (2015). Anell de Pedra. La Comella, 19762001. Rufino Mesa. Barcelona, Research, Art, Creation, 3(1), 1-12. doi: 10.4471/brac.2015.01

To link this article: http://dx.doi.org/10.4471/brac.2015.01

\section{PLEASE SCROLL DOWN FOR ARTICLE}

The terms and conditions of use, except where otherwise noted, are related to the Open Journal System and to Creative Commons Attribution License (CCBY). The indication must be expressly stated when necessary. 


\section{Stone ring. La Comella, 1976- 2001. Rufino Mesa}

Rufino Mesa

Artist and Doctor of Fine Arts

\section{Abstract}

The day when the rocks, which form the Stone ring, were moved from Reus and installed in La Comella (Tarragona), the voice left and I deeply get to know the value of fatigue.

I could not talk then but I realized that each one of the stones had an identity and that since that moment all them together will form an idea: now it is the right moment to present the observation.... 


\section{Anillo de Piedra. La Comella, 1976-2001. Rufino Mesa}

Rufino Mesa

Artista y Doctor en Bellas Artes

\section{Resumen}

El día que desde Reus transportamos las rocas que forman el Círculo de piedra y que instalamos en La Comella (Tarragona), perdí la voz y conocí en esencia el valor de la fatiga.

En ese momento me fue imposible hablar, pero pensé que cada piedra tenía una identidad y que desde aquel instante todas ellas formarían una idea: creo que ahora es el momento oportuno para presentar la observación.... 


\section{Anell de pedra. La Comella, 1976-2001. Rufino Mesa}

Rufino Mesa

Artista i Doctor en Belles Arts

\section{Resum}

El dia que vam transportar des de Reus les roques que formen l'Anell de pedra i les vam instal·lar a La Comella (Tarragona), la veu em va marxar i vaig conèixer en profunditat el valor de la fatiga.

Llavors no podia parlar però vaig pensar que cada pedra tenia una identitat i des de llavors totes elles formarien una idea: ara penso que és el moment oportú per a presentar l'observació... 


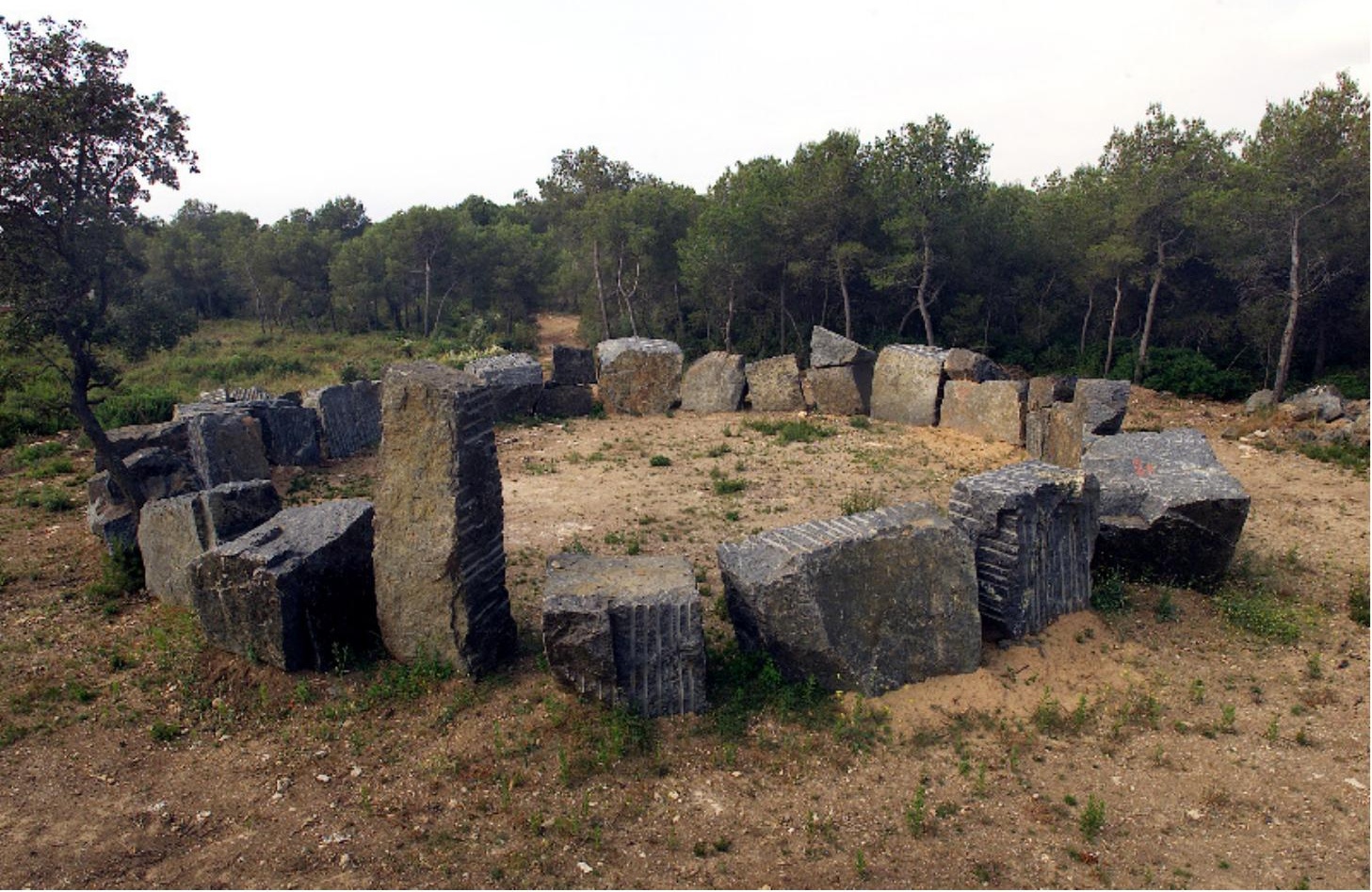

Figura 1. "Anell de pedra". La Comella, 1976-2001.

$17 \mathrm{~m}$. de diàmetre x 3,20 m. d'alçada. Granit negre de la ex. U. R. S. S.

(C) Rufino Mesa 


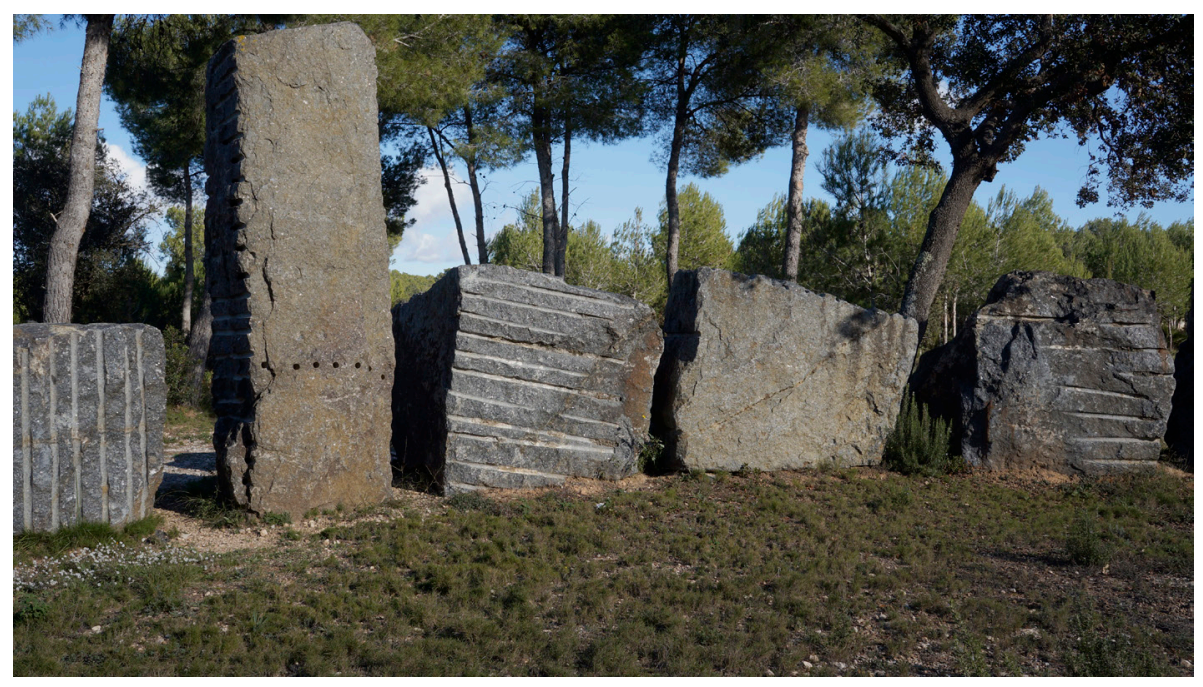

Figura 2. “Anell de pedra". La Comella, 1976-2001. (Detall). (C) Rufino Mesa 


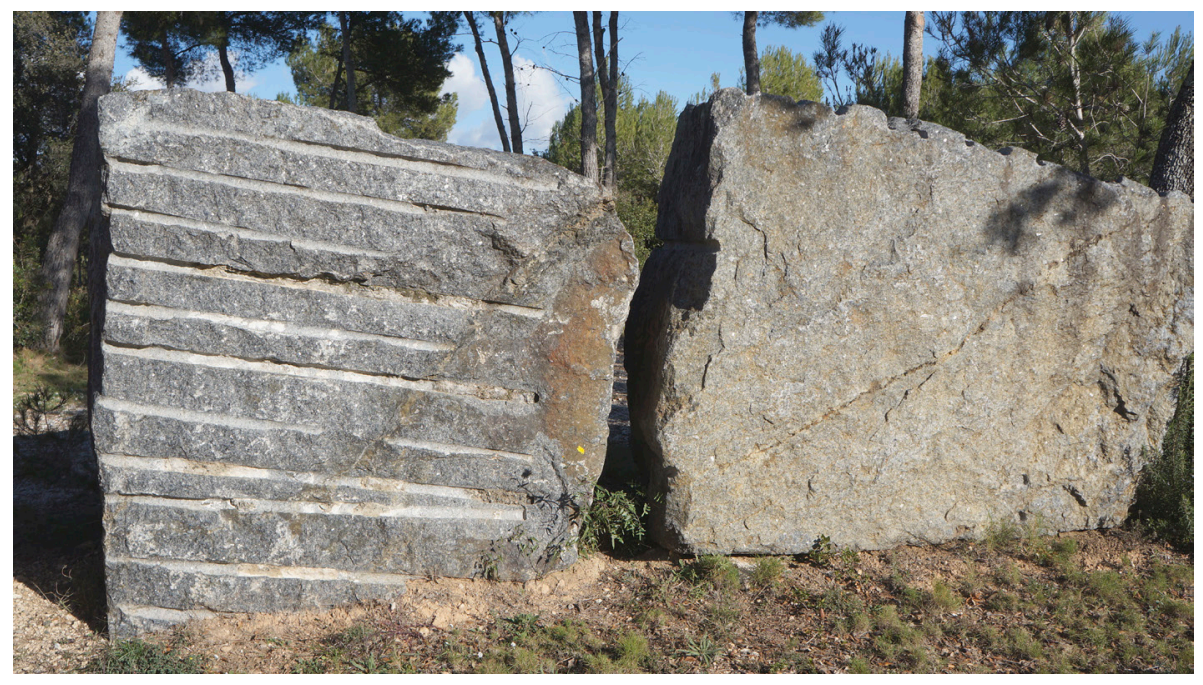

Figura 3. “Anell de pedra". La Comella, 1976-2001. (Detall). (C) Rufino Mesa 


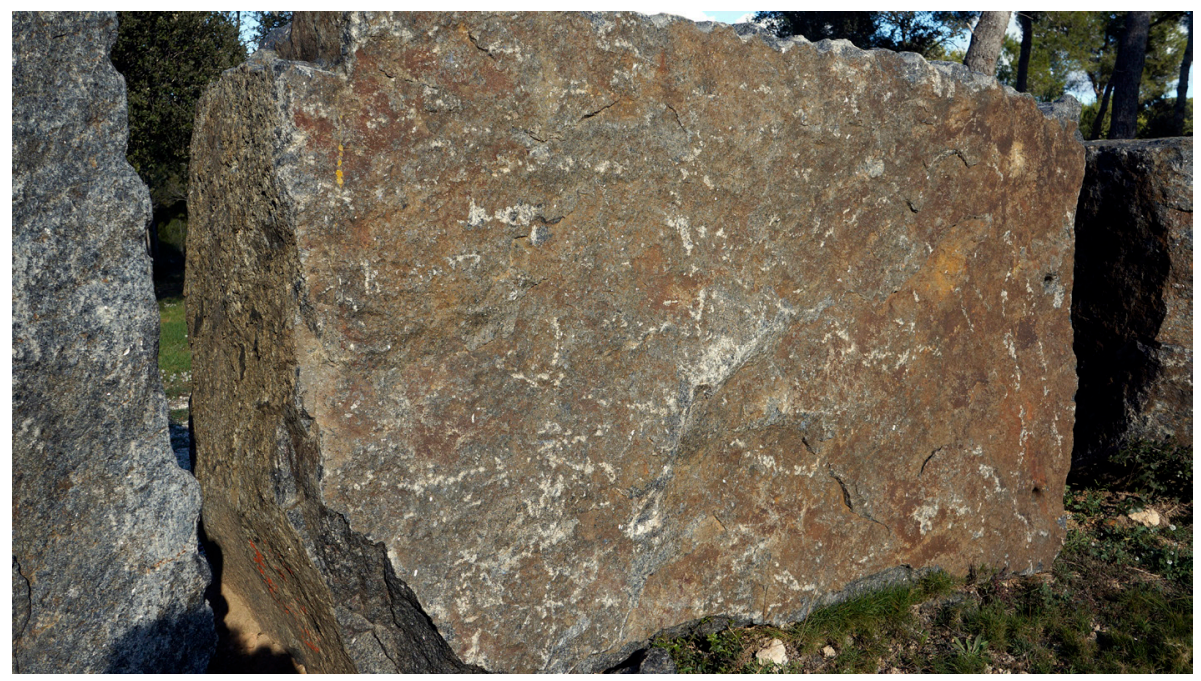

Figura 4. “Anell de pedra". La Comella, 1976-2001. (Detall). (C) Rufino Mesa 


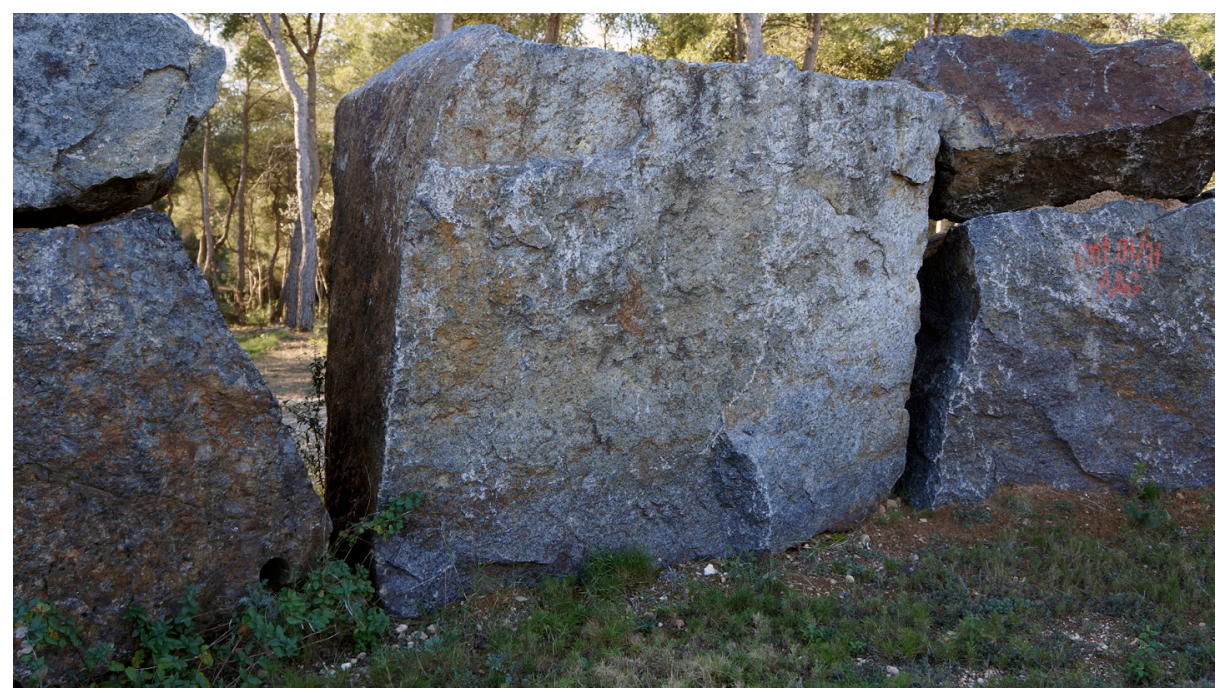

Figura 5. “Anell de pedra". La Comella, 1976-2001. (Detall). (C) Rufino Mesa 
$\mathbf{R}$

eplicant les construccions dels pastors de les muntanyes d'Urbasa, d'Andía, d'Aralar, el 1976 vaig iniciar un treball efímer, senzill i compromès: una aliança en forma d'anell. Era una idea aparentment sense gravetat, una acció per al consum personal, la moixaina del vent en la contemplació instantània, però per a mi va ser l'inici dels anells del pacte, un treball que posteriorment ocuparia part important de la meva vida. Amb un bastó gratava el terra i configurava un cercle que, seguidament, contemplava com si d'una aparició es tractés. Anells petits (no més de metre i mig, alguns de $70 \mathrm{~cm}$.) dibuixats amb herbes, terra, pedres, llaunes o directament a la sorra de la platja. Les incipients arquitectures eren d'expressió mínima i es presentaven com caixes obertes que s'emmirallaven amb el sol. No informaven de res especial a excepció de la màgia que es desprèn de l'estètica del cercle: posteriorment sí, la forma va adquirir un compromís remarcable.

A diferència del joc simbòlic que es va formular amb l'anell, els cercles de pedra d'Urbasa, d'Aralar i Andía eren de naturalesa diferent. Els cromlec dels pastors neolítics, no eren símbols d'un pacte, tampoc eren espais funeraris, eren construccions de pedres de funció desconeguda segons afirma Barandiarán. Presenten el seu espai intern orfe de funció concreta i el buit interior, el no res i la seva naturalesa enigmàtica, va ser la que va captivar Oteiza (1973) segons ell mateix em va dir. Ell deia que la valoració i contemplació quedava continguda dins del misteri, s'havia de mirar des de fora, al·legoria de l'estètica per l'estètica com passa en les obres de Richard Long.

Com he dit aquest no va ser el valor que jo cercava a les construccions circulars. Tot plegat vaig buscar la funció simbòlica del pacte, el compromís amb la natura i el treball posterior dirigit a fer d'una roca un jardí restaurat: la Comella. El cercle ha estat l'expressió d'una aliança amb la vida i la seva aplicació formal i conceptual ha quedat a les terres que envolten el meu taller. http://lacomella.org/

\section{El Lloc}

Com he dit el testimoni material de l'aliança ha quedat a la "Comella, Escultura i Natura” (CEN) És un bosc mediterrani de $78.000 \mathrm{~m} 2$, amb unes 120 obres que tracten diferents aspectes de l'experiència de viure. És un centre privat amb voluntat pública. Tot el conjunt (escultures, arranjament de la ma- 
sia i neteja del bosc), ha estat elaborat com "una obra" on la natura és l'eix i el motiu principal de la reflexió estètica. Amb el temps s'ha esdevingut en un parc d'escultures on queda explícita, clarament induïda, la reflexió sobre l'art i la vida. El treball és respectuós amb la història i manté un compromís amb la terra per crear un sistema sostenible. CEN és el resultat de 40 anys de recerques, un treball continuat que ha tingut la voluntat de viure l'art contemporani i la natura com una forma d'entregar-se i proporcionar sentit a la vida.

Aquí recordaré unes paraules de Arvol Looking Horse (1994), un indi Lacotà que reclamava la necessitat del pacte $\mathrm{i}$ un rostre reconciliador amb la natura, unes paraules que tenen avui tota la vigència.

Nos hallamos ahora en una etapa crítica de nuestro desarrollo espiritual, moral y tecnológico como naciones. Toda la vida se encuentra en un equilibrio precario. Hemos de recordar que todas las coses de la Madre Tierra poseen un espíritu y se hallan intrincadamente relacionadas. Ha comenzado a cumplirse la profecía lakota de recomponer el sagrado anillo de todas las naciones. En la antigua sabiduría de las naciones indígenas, podemos hallar el espíritu y el valor para enmendar y curar. (p. 36)

\section{Cercle i Concepte}

A l'època moderna la presència del cercle és virtual, la formen els electrons al voltant del nucli i són presències furtives, "mandales" meravellosos a l'espai interior de la matèria. És un escenari teòric on podem fer un ritual per a la pregària pagana $\mathrm{i}$ on podem ocultar la incertesa de la nostra acció espiritual. Allí es troba el principi de la bellesa i el santuari de la postmodernitat, el que presenta la física quàntica i demana una atenció espiritual renovada. Penso que, com en una roca mil·lenària, allí s'ha d'escriure una paraula, no amb neó com faria Joseph Kosuth, sinó amb el bategar del cor i el pols de la intenció. Aquest escenari és el mateix que fa milers d'anys s'havia intuït i presentat des de la visió poètica i religiosa $\mathrm{i}$ ara, en l'era del buit i les estratègies del simulacre és un material conceptual per fer l'obra. En el moment de la instrumentació del desig i la llibertat absoluta, quan les idees s'han esfondrat $i$ han quedat engolides sobre si mateixes, no queda altre camí que l'actitud resignada en aquest espai, la convicció en les idees que es depositen allí, o pot ser, en la direcció neuròtica de l'ocultació. 


\section{El Compromís}

Aquells cercles, els dels anys de la meva formació, eren presidits pels seus silencis, per la seva lluminositat i foscor. En aquell moment calia fer l'obra al marge del mercat i el glamur dels museus: confesso que vaig creure plenament en tot el discurs i vaig ser un alumne aplicat. Llavors érem joves, vivíem l'època conceptual i l'ètica del compromís: l'obra havia d'estar arrelada en la vida i la idea sempre havia de ser més important que la forma.

Aquells espais desocupats, aquelles àrees buides, em van captivar i van configurar l'inici de les ocultacions i la gran aventura de la meva vida. Treballar en la cara fosca de la realitat ha estat apassionant i m'ha proporcionat grans dosis de llibertat. En realitat les obres eren excuses per dir allò que volia dir i he de manifestar que així ho he fet. En aquells espais hipotètics trobava un fons caòtic d'infinites transformacions, un escenari que creixia en totes les direccions i captivava el pensament con una melodia: tot plegat era un camí per a expressar-me en llibertat. Era un oceà sense límits aparents on les idees suraven i naixien de manera incessant.

En "Palabra oscura" (obra unida conceptualment a l'anell i que recull el compromís personal envers la natura), vaig viure una experiència única. Per un instant allí s'exhibia sobre el fang l'objecte de la meva realitat mental. L'escultura està formada per sis caixes de bronze amb els documents testamentaris: boles de fang plenes de paraules que ara s'exposen a la Biblioteca Xavier Amorós de Reus.

Després de la feina feta, dels dubtes que he gestionat, penso que persistir en la presentació de les idees en aquest espai i fer-lo sense la complicitat i el reconeixement social és un suïcidi intel·lectual, una quimera que delata certa neurosi, però jo vaig estar treballant-hi 40 anys i encara aguanto el camí traçat amb la mateixa convicció.

\section{El Pacte}

L'espai de l'anell no eren territoris per les divinitats, eren llocs naturals on la creació material m'invitava a actuar en la seva pell lluminosa: acció per deixar en silenci el registre de la paraula i a la terra la intervenció restauradora, la carícia entregada a la natura. El pacte no és una idea peregrina i estic disposat a continuar per aquest camí carregat de futur encara que hagi de pagar un preu elevat. 
Els defectes que pot patir l'art que renuncia a la presentació formal s'han de tenir en compte. D'entrada pot allunyar-se de la realitat social i presentar-se com un compromís moral, una opció política o estètica ennuvolada i confosa. No crec però que aquest sigui el problema més greu que presento al llarg de la meva vida: com el silenci, les paraules ocultes també podem escoltar-les. La societat moderna ens ha arrencat la confiança en aquests valors mistèrics i crec que la forma de restaurar-los és, precisament, presentant l'absència del sentit. L'obra instal·lada en el lloc del sacrifici, a l'espai de la renuncia. Amagar la tenacitat de l'autor tot ocultant les idees, deixant l'ànima de l'obra secreta però pressentida i clandestina dins la Caixa que s'esborra al fons.

Rufino Mesa 29 de desembre de 2014

\section{Referencias}

Oteiza, J. (1973). Quosque tanden...! Estella. Verbo Divino. 44, 96.

Gran Jefe Seattle. (1994). Nosotros somos parte de la tierra. Mensaje del gran jefe Seattle al Presidente de los Estados Unidos en el año de 1855. Palma de Mallorca. Hesperus. 36. 